\title{
Perioperative lung-protective ventilation strategy reduces postoperative pulmonary complications in patients undergoing thoracic and major abdominal surgery
}

\author{
Sang-Heon Park ${ }^{1,2}$ \\ ${ }^{1}$ Department of Anesthesiology, Sheikh Khalifa Specialty Hospital, RAK, UAE, ${ }^{2}$ Department of Anethesiology and \\ Pain Medicine, Seoul National University Hospital, Seoul, Korea
}

The occurrence of postoperative pulmonary complications is strongly associated with increased hospital mortality and prolonged postoperative hospital stays. Although protective lung ventilation is commonly used in the intensive care unit, low tidal volume ventilation in the operating room is not a routine strategy. Low tidal volume ventilation, moderate positive end-expiratory pressure, and repeated recruitment maneuvers, particularly for high-risk patients undergoing major abdominal surgery, can reduce postoperative pulmonary complications. Facilitating perioperative bundle care by combining prophylactic and postoperative positive-pressure ventilation with intraoperative lung-protective ventilation may be helpful to reduce postoperative pulmonary complications.

Key Words: Lung-protective ventilation, Mechanical ventilation, Pulmonary complications.

\section{Introduction}

The occurrence of postoperative pulmonary complications (PPCs) is strongly associated with increased hospital mortality and prolonged postoperative hospital stays. The mortality rate associated with PPCs is $10 \%$ to $20 \%$ after major surgery [1]. One

Corresponding author: Sang-Heon Park, M.D., Ph.D.

Department of Anethesiology, Sheikh Khalifa Specialty Hospital, PO box 6365, Truck road, Ras Al Khamimah, UAE

Tel: 971561874248, Fax: 971-7-244-4437

E-mail: sanghon.park@sksh.ae

Received: November 19, 2015.

Revised: December 3, 2015.

Accepted: December 4, 2015.

Korean J Anesthesiol 2016 February 69(1): 3-7

http://dx.doi.org/10.4097/kjae.2016.69.1.3 cohort study of 33769 surgical cases [2] showed that unplanned reintubation within the first 3 postoperative days is highly associated with a 72 -fold increased risk of death. Therefore, preventing these complications has become a high priority of intraoperative and postoperative anesthetic management.

Mechanical ventilation is mandatory during general anesthesia in patients undergoing surgical procedures. Setting a tidal volume (VT) of $\geq 10 \mathrm{ml} / \mathrm{kg}$ in anesthetized patients undergoing surgery has been advocated to prevent atelectasis and hypoxemia. However, the results of many experimental and clinical studies have suggested that high-VT ventilation may cause or aggravate lung injury. Lung-protective ventilation reduces morbidity and mortality among patients with acute lung injury (ALI) and acute respiratory distress syndrome [3,4]. Lung-protective ventilation uses a low tidal volume and moderate positive endexpiratory pressure (PEEP) with an intermittent recruitment maneuver (RM). However, intraoperative $\mathrm{VT}$ of $\geq 10 \mathrm{ml} / \mathrm{kg}$ is

(c) This is an open-access article distributed under the terms of the Creative Commons Attribution Non-Commercial License (http://creativecommons.org/ licenses/by-nc/4.0/), which permits unrestricted non-commercial use, distribution, and reproduction in any medium, provided the original work is properly cited. 
only used in $18 \%$ of cases during surgery, and low tidal volume ventilation is not a routine strategy [5]. In this review, the currently used perioperative ventilation strategies and the rationale for using a lung-protective ventilation strategy will be addressed. Furthermore, we discuss perioperative surgical factors and recent advances for reducing PPCs.

\section{Perioperative Tidal Volume and PEEP}

A VT of 10 to $15 \mathrm{ml} / \mathrm{kg}$ has been advocated to maintain normal ventilation and prevent atelectasis caused by low-VT ventilation in anesthetized patients undergoing surgery [6]. Although lung-protective ventilation has become the routine ventilator strategy in the intensive care unit (ICU), some reports indicate that the incidence of using high-VT ventilation in the operating room is not low. Two retrospective observational studies [5,7] reported that about $30 \%$ of adult patients receive a high VT of $>10 \mathrm{ml} / \mathrm{kg}$ of their ideal body weight and that high-risk patients continue to receive nonprotective ventilation, although the use of nonprotective ventilation has decreased over time. In addition, Blum et al. [8] reported no difference in the intraoperative ventilation strategy between patients with and without ALI, suggesting that anesthesiologists do not routinely implement lungprotective ventilation in patients with known ALI.

Whether intraoperative PEEP reduces the risk of postoperative mortality and pulmonary outcomes remains unclear [9]. One randomized controlled trial in nonobese patients undergoing planned abdominal surgery showed that a high PEEP (12 $\mathrm{cmH}_{2} \mathrm{O}$ ) and $\mathrm{RM}$ strategy during open abdominal surgery was not associated with a lower incidence of postoperative pulmonary complications than was a low PEEP level $\left(0-2 \mathrm{cmH}_{2} \mathrm{O}\right)[10]$. Moreover, Levin et al. [11] reported that a low VT with PEEP of 2.2 to $5.0 \mathrm{cmH}_{2} \mathrm{O}$ increases the 30 -day mortality rate and hospital length of stay. A meta-analysis confirmed that a high PEEP does not prevent postoperative pulmonary complications when a low VT is used [12]. The optimal PEEP level for lung-protective ventilation remains underdetermined, but a PEEP level of $>5 \mathrm{cmH}_{2} \mathrm{O}$ is recommended in obese patients or patients undergoing laparoscopic surgery $[13,14]$.

\section{Beneficial Effects of Lung-protective Ventilation}

Causality between intraoperative atelectasis and PPCs has not been clearly demonstrated. Nevertheless, atelectasis can develop anytime during anesthesia and last into the early postoperative period. Impaired oxygenation, forced vital capacity, and forced expired volume in $1 \mathrm{sec}$ are significantly correlated with the atelectatic area confirmed by computed tomography [15]. Moreover, the distal airway can be injured by regional atelectasis, but injury is not localized to atelectatic regions; it can also occur in remote nonatelectatic areas [16]. As a result, the pathophysiological changes associated with atelectasis can impair oxygenation, decrease compliance, increase pulmonary vascular resistance, and injure the lungs [17].

Biotrauma from mechanical ventilation can develop into multiple system organ failure due to release of lung-originating inflammatory mediators into the systemic circulation [18]. Imai et al. [19] showed that an $8 \mathrm{~h}$ injurious ventilation strategy in a rabbit model can result in increased rates of kidney and small intestinal epithelial cell apoptosis accompanied by biochemical evidence of organ dysfunction. Short-term nonprotective mechanical ventilation ( $\geq 5 \mathrm{~h}$ ) supports local bronchoalveolar inflammatory changes and activates coagulation in patients without preexisting lung injury [20,21].

\section{Nonventilatory Factors Influencing PPCs}

Many risk factors predispose patients to PPCs and can be divided into patient-related and surgery-related factors. The surgical site is the most important predictor of overall PPCs. Patients undergoing thoracic or upper abdominal surgery have a high incidence of PPCs because of the close proximity of the surgical incision to the diaphragm. In addition, laparoscopic abdominal surgery operations can lower reoperation rates and pulmonary complications compared with open surgery [22].

Atelectasis is mainly caused after an open laparotomy in up to $90 \%$ of patients under general anesthesia [17]. Suitable epidural pain control significantly reduces the incidence of pulmonary complications (atelectasis, pneumonia, and respiratory failure) after major thoracic and abdominal surgery [23-25]. The effects of epidural analgesia can vary depending on the severity of the underlying lung disease. Patients with chronic obstructive pulmonary disease seem to derive the most benefit from epidural analgesia [26].

\section{One-lung Ventilation}

ALI after thoracic surgery has been reported since the first use of one-lung ventilation during lung surgery. Many studies have investigated the risk factors for, pathogenesis of, and management of postoperative ALI. A retrospective study reported that the prevalence of post-pneumonectomy pulmonary edema was $2.5 \%$ and the mortality rate was $100.0 \%$ in affected patients [27]. Similar to two-lung ventilation, high tidal volumes during one-lung ventilation can cause or contribute to PPCs. A retrospective study of patients who underwent pneumonectomy showed that a peak airway pressure of $>40 \mathrm{cmH}_{2} \mathrm{O}$ during surgery is correlated with the occurrence of PPCs [28]. Another study found that patients receiving higher intraoperative VT (8.3 
$\mathrm{ml} / \mathrm{kg}$, predicted body weight) have a higher incidence of postpneumonectomy respiratory failure than do patients with a low VT $(6.7 \mathrm{ml} / \mathrm{kg})$ [29]. Frequent alveolar RM can be applied to avoid ALI after adding low-VT ventilation [30]. Licker et al. [31] reported that a lung-protective ventilation strategy with frequent RM results in a decreased incidence of ALI and atelectasis and a shorter hospital stay in patients undergoing lung cancer surgery compared with patients who received a conventional ventilation strategy.

\section{Cardiopulmonary Bypass (CPB)}

Postoperative pulmonary dysfunction is an obvious complication after $\mathrm{CPB}$. While the systemic inflammatory response syndrome induced by $\mathrm{CPB}$ plays a major role, pulmonary dysfunction is generated from a variety of factors that are not all associated with CPB itself. Protective ventilatory strategies can be helpful for preventing PPCs after $\mathrm{CPB}$. A lung-protective low tidal volume $(8 \mathrm{ml} / \mathrm{kg})$ plus high PEEP $\left(10 \mathrm{cmH}_{2} \mathrm{O}\right)$ was applied for $6 \mathrm{~h}$ after $\mathrm{CPB}$ in patients who underwent coronary artery bypass surgery [32]. Serum and bronchiolar lavage levels of the inflammatory cytokines interleukin (IL)- 6 and IL- 8 were significantly lower at $6 \mathrm{~h}$ than in a nonprotective ventilation group with high tidal volumes (10-12 ml/kg) plus low PEEP (2-3 $\left.\mathrm{cmH}_{2} \mathrm{O}\right)$. Sundar et al. [33] compared extubation between patients undergoing elective cardiac surgery who received a low VT $(6 \mathrm{ml} / \mathrm{kg})$ and high VT $(10 \mathrm{ml} / \mathrm{kg})$. They reported that more patients were extubated in the low VT group at $8 \mathrm{~h}$ and that these patients also had a lower reintubation rate postoperatively. A cohort study of 3434 patients undergoing cardiac surgery demonstrated that a high VT is an independent risk factor for multiple organ failure and prolonged ICU stay [34].

\section{Recruitment Maneuver and Perioperative Positive-pressure Ventilation}

A well-designed study investigated postoperative lung function in patients on low VT ventilation without RM during upper abdominal surgery [35]. However, no significant benefit on postoperative lung function was demonstrated. Low-VT ventilation is reported to promote atelectasis [6]. RMs are used to reinflate collapsed alveoli, sustained pressure above the tidal ventilation range is applied, and PEEP is used to prevent derecruitment with use of a lower VT [17].

Severgnini et al. [36] examined the effects of intraoperative low VT, higher PEEP level, and RMs during open abdominal surgery lasting $2 \mathrm{~h}$. That study showed that lung-protective ventilation improves respiratory function and reduces the modified clinical pulmonary infection score after surgery. However, no difference was observed in the length of hospital stay between the groups. The Intraoperative PROtective VEntilation (IMPROVE) trial was performed with low-VT ventilation, moderate PEEP, and repeated RMs, particularly for high-risk patients undergoing major abdominal surgery [37]. It demonstrated that the incidence of PPCs within the first 7 days after surgery was lower with lung-protective ventilation than without ventilation. The proportion of patients on noninvasive ventilation or intubation was lower in the protective ventilation group during the first 7 days postoperatively. Importantly, the length of hospital stay was also shorter in the protective ventilation group.

The facilitation of perioperative bundle care by combining prophylactic and postoperative positive-pressure ventilation with intraoperative lung-protective ventilation [38] may be more helpful in reducing postoperative morbidity. The purpose of this ventilation strategy is to minimize lung volume reduction throughout the pre-, intra-, and postoperative periods. In this strategy, preoperative noninvasive positive-pressure ventilation using pressure support ventilation (PSV) and PEEP or continuous positive-pressure ventilation (CPAP) effectively attenuates reduced lung volume. Lung-protective ventilation is continued throughout the surgical procedure. The same noninvasive respiratory support (PSV + PEEP or CPAP) is performed during the early postoperative period. Finally, performing postoperative CPAP or PSV and PEEP improves gas exchange and pulmonary function after extubation for major thoracic and abdominal surgery and could help prevent postoperative acute respiratory failure in patients at high risk for PPCs [39].

\section{Conclusion}

Preventing PPCs has become a high priority of intraoperative and postoperative management. Although lung-protective ventilation has become routine in the ICU, low-VT ventilation in the operating room is not a routine strategy. Low-VT ventilation, moderate PEEP, and repeated RMs, particularly for high-risk patients undergoing major abdominal surgery, can reduce PPCs. Facilitating perioperative bundle care by combining prophylactic and postoperative positive-pressure ventilation with intraoperative lung-protective ventilation may be more helpful in reducing PPCs. Further investigations are needed to determine how results can be applied and implemented in routine clinical practice. 


\section{References}

1. Khuri SF, Henderson WG, DePalma RG, Mosca C, Healey NA, Kumbhani DJ. Determinants of long-term survival after major surgery and the adverse effect of postoperative complications. Ann Surg 2005; 242: 326-41.

2. Brueckmann B, Villa-Uribe JL, Bateman BT, Grosse-Sundrup M, Hess DR, Schlett CL, et al. Development and validation of a score for prediction of postoperative respiratory complications. Anesthesiology 2013; 118: 1276-85.

3. Petrucci N, De Feo C. Lung protective ventilation strategy for the acute respiratory distress syndrome. Cochrane Database Syst Rev 2013; 2: CD003844.

4. Putensen C, Theuerkauf N, Zinserling J, Wrigge H, Pelosi P. Meta-analysis: ventilation strategies and outcomes of the acute respiratory distress syndrome and acute lung injury. Ann Intern Med 2009; 151: 566-76.

5. Jaber S, Coisel Y, Chanques G, Futier E, Constantin JM, Michelet P, et al. A multicentre observational study of intra-operative ventilatory management during general anaesthesia: tidal volumes and relation to body weight. Anaesthesia 2012; 67: 999-1008.

6. Bendixen HH, Hedley-Whyte J, Laver MB. Impaired oxygenation in surgical patients during general anesthesia with controlled ventilation. A concept of atelectasis. N Engl J Med 1963; 269: 991-6.

7. Hess DR, Kondili D, Burns E, Bittner EA, Schmidt UH. A 5-year observational study of lung-protective ventilation in the operating room: a single-center experience. J Crit Care 2013; 28: 533. e9-15.

8. Blum JM, Maile M, Park PK, Morris M, Jewell E, Dechert R, et al. A description of intraoperative ventilator management in patients with acute lung injury and the use of lung protective ventilation strategies. Anesthesiology 2011; 115: 75-82.

9. Imberger G, McIlroy D, Pace NL, Wetterslev J, Brok J, Møller AM. Positive end-expiratory pressure (PEEP) during anaesthesia for the prevention of mortality and postoperative pulmonary complications. Cochrane Database Syst Rev 2010: (9): CD007922.

10. PROVE Network Investigators for the Clinical Trial Network of the European Society of Anaesthesiology, Hemmes SN, Gama de Abreu M, Pelosi P, Schultz MJ. High versus low positive end-expiratory pressure during general anaesthesia for open abdominal surgery (PROVHILO trial): a multicentre randomised controlled trial. Lancet 2014; 384: 495-503.

11. Levin MA, McCormick PJ, Lin HM, Hosseinian L, Fischer GW. Low intraoperative tidal volume ventilation with minimal PEEP is associated with increased mortality. Br J Anaesth 2014; 113: 97-108.

12. Neto AS, Simonis FD, Barbas CS, Biehl M, Determann RM, Elmer J, et al. Lung-protective ventilation with low tidal volumes and the occurrence of pulmonary complications in patients without acute respiratory distress syndrome: a systematic review and individual patient data analysis. Crit Care Med 2015; 43: 2155-63.

13. Futier E, Constantin JM, Pelosi P, Chanques G, Kwiatkoskwi F, Jaber S, et al. Intraoperative recruitment maneuver reverses detrimental pneumoperitoneum-induced respiratory effects in healthy weight and obese patients undergoing laparoscopy. Anesthesiology 2010; 113: 1310-9.

14. Reinius H, Jonsson L, Gustafsson S, Sundbom M, Duvernoy O, Pelosi P, et al. Prevention of atelectasis in morbidly obese patients during general anesthesia and paralysis: a computerized tomography study. Anesthesiology 2009; 111: 979-87.

15. Lindberg P, Gunnarsson L, Tokics L, Secher E, Lundquist H, Brismar B, et al. Atelectasis and lung function in the postoperative period. Acta Anaesthesiol Scand 1992; 36: 546-53.

16. Tsuchida S, Engelberts D, Peltekova V, Hopkins N, Frndova H, Babyn P, et al. Atelectasis causes alveolar injury in nonatelectatic lung regions. Am J Respir Crit Care Med 2006; 174: 279-89.

17. Duggan M, Kavanagh BP. Pulmonary atelectasis: a pathogenic perioperative entity. Anesthesiology 2005; 102: 838-54.

18. Plötz FB, Slutsky AS, van Vught AJ, Heijnen CJ. Ventilator-induced lung injury and multiple system organ failure: a critical review of facts and hypotheses. Intensive Care Med 2004; 30: 1865-72.

19. Imai Y, Parodo J, Kajikawa O, de Perrot M, Fischer S, Edwards V, et al. Injurious mechanical ventilation and end-organ epithelial cell apoptosis and organ dysfunction in an experimental model of acute respiratory distress syndrome. JAMA 2003; 289: 2104-12.

20. Wolthuis EK, Choi G, Dessing MC, Bresser P, Lutter R, Dzoljic M, et al. Mechanical ventilation with lower tidal volumes and positive endexpiratory pressure prevents pulmonary inflammation in patients without preexisting lung injury. Anesthesiology 2008; 108 : 46-54.

21. Choi G, Wolthuis EK, Bresser P, Levi M, van der Poll T, Dzoljic M, et al. Mechanical ventilation with lower tidal volumes and positive endexpiratory pressure prevents alveolar coagulation in patients without lung injury. Anesthesiology 2006; 105: 689-95.

22. Weller WE, Rosati C. Comparing outcomes of laparoscopic versus open bariatric surgery. Ann Surg 2008; 248: 10-5.

23. Ballantyne JC, Carr DB, deFerranti S, Suarez T, Lau J, Chalmers TC, et al. The comparative effects of postoperative analgesic therapies on pulmonary outcome: cumulative meta-analyses of randomized, controlled trials. Anesth Analg 1998; 86: 598-612.

24. Liu SS, Wu CL. Effect of postoperative analgesia on major postoperative complications: a systematic update of the evidence. Anesth Analg 2007; 104: 689-702.

25. Rigg JR, Jamrozik K, Myles PS, Silbert BS, Peyton PJ, Parsons RW, et al. Epidural anaesthesia and analgesia and outcome of major surgery: a randomised trial. Lancet 2002; 359: 1276-82.

26. Licker MJ, Widikker I, Robert J, Frey JG, Spiliopoulos A, Ellenberger C, et al. Operative mortality and respiratory complications after lung resection for cancer: impact of chronic obstructive pulmonary disease and time trends. Ann Thorac Surg 2006; 81: 1830-7.

27. Turnage WS, Lunn JJ. Postpneumonectomy pulmonary edema. A retrospective analysis of associated variables. Chest 1993; 103: 1646-50. 
28. van der Werff YD, van der Houwen HK, Heijmans PJ, Duurkens VA, Leusink HA, van Heesewijk HP, et al. Postpneumonectomy pulmonary edema. A retrospective analysis of incidence and possible risk factors. Chest 1997; 111: 1278-84.

29. Fernández-Pérez ER, Keegan MT, Brown DR, Hubmayr RD, Gajic O. Intraoperative tidal volume as a risk factor for respiratory failure after pneumonectomy. Anesthesiology 2006; 105: 14-8.

30. Mols G, Priebe HJ, Guttmann J. Alveolar recruitment in acute lung injury. Br J Anaesth 2006; 96: 156-66.

31. Licker M, Diaper J, Villiger Y, Spiliopoulos A, Licker V, Robert J, et al. Impact of intraoperative lung-protective interventions in patients undergoing lung cancer surgery. Crit Care 2009; 13: R41.

32. Zupancich E, Paparella D, Turani F, Munch C, Rossi A, Massaccesi S, et al. Mechanical ventilation affects inflammatory mediators in patients undergoing cardiopulmonary bypass for cardiac surgery: a randomized clinical trial. J Thorac Cardiovasc Surg 2005; 130: 378-83.

33. Sundar S, Novack V, Jervis K, Bender SP, Lerner A, Panzica P, et al. Influence of low tidal volume ventilation on time to extubation in cardiac surgical patients. Anesthesiology 2011; 114: 1102-10.

34. Lellouche F, Dionne S, Simard S, Bussieres J, Dagenais F. High tidal volumes in mechanically ventilated patients increase organ dysfunction after cardiac surgery. Anesthesiology 2012; 116: 1072-82.

35. Treschan TA, Kaisers W, Schaefer MS, Bastin B, Schmalz U, Wania V, et al. Ventilation with low tidal volumes during upper abdominal surgery does not improve postoperative lung function. Br J Anaesth 2012; 109: 263-71.

36. Severgnini P, Selmo G, Lanza C, Chiesa A, Frigerio A, Bacuzzi A, et al. Protective mechanical ventilation during general anesthesia for open abdominal surgery improves postoperative pulmonary function. Anesthesiology 2013; 118: 1307-21.

37. Futier E, Constantin JM, Paugam-Burtz C, Pascal J, Eurin M, Neuschwander A, et al. A trial of intraoperative low-tidal-volume ventilation in abdominal surgery. N Engl J Med 2013; 369: 428-37.

38. Futier E, Marret E, Jaber S. Perioperative positive pressure ventilation: an integrated approach to improve pulmonary care. Anesthesiology 2014; 121: 400-8.

39. Jaber S, Chanques G, Jung B. Postoperative noninvasive ventilation. Anesthesiology 2010; 112: 453-61. 